\title{
Effects of weight loss on a low-carbohydrate diet on flow-mediated dilatation, adhesion molecules and adiponectin
}

\author{
Jennifer B. Keogh*, Grant D. Brinkworth and Peter M. Clifton \\ CSIRO Human Nutrition, PO Box 10041 BC, Adelaide SA 5000, Australia
}

(Received 17 January 2006 - Revised 9 March 2007 - Accepted 21 March 2007)

Our aim was to determine whether short-term weight loss on a low-carbohydrate/low-saturated fat diet improved endothelial function compared with a conventional high-carbohydrate diet, as this diet is expected to lower both blood glucose and LDL-cholesterol. In a randomised parallel design of two energy-restricted diets in an outpatient setting, thirty-six subjects (BMI 33 (SEM 4) kg/m²) were randomised to a low- or high-carbohydrate diet both low in saturated fat. Flow-mediated dilatation (FMD), fasting glucose, insulin, lipids, adiponectin and adhesion molecules were measured at baseline, during weight loss and at 52 weeks. FMD did not change with either diet (5.2 (SEM 0.6) to 5.5 (SEM 0.6) \%) despite weight loss of $5 \%$ and significant reductions in glucose and insulin and LDL-cholesterol and was not different after sustained weight loss of $5 \%$ at 52 weeks. Adiponectin fell by $6 \%$ at 12 weeks $(P=0 \cdot 1)$ with weight loss but rose by $17 \%$ at 12 months $(P<0 \cdot 05)$ with $5 \%$ weight loss. There were no effects of diet. In contradistinction, adhesion molecules fell at 12 weeks, vascular cell adhesion molecule-1 by $14 \%$ and intracellular adhesion molecule- 1 by $13 \%$ (both $P<0.05$ ). There were correlations between change in adiponectin at 12 months and change in HDL $(r 0.778, P<0 \cdot 01$ ) and glucose $(r-0.563, P=0.057)$. In summary, weight loss does not improve FMD. Novel cardiovascular risk factors improved at 12 weeks but the improvement in adiponectin was delayed.

Endothelium: Weight loss: Low-carbohydrate diet: Flow-mediated dilatation: Adhesion molecules

Obesity is associated with impaired endothelial function assessed by flow-mediated dilatation $(\mathrm{FMD})^{1}$ but the evidence that weight loss improves FMD is contradictory. There are several studies showing that reductions in LDL-cholesterol (LDL-C) and fasting glucose concentrations but not weight loss per se were associated with improvements in $\mathrm{FMD}^{2,3}$. The effect on FMD of dietary composition has not been extensively examined and has largely focused on the effect of dietary fat on FMD in a weight-stable setting ${ }^{4-7}$. To our knowledge there is only one study of the effect of a low-carbohydrate diet on endothelial function during weight loss and this was conducted using a very-low-caloric diet ${ }^{3}$. Weight loss per se is usually associated with reductions in $\mathrm{LDL}^{8} \mathrm{C}^{8}$ and reducing saturated fat also decreases $\mathrm{LDL}^{-}{ }^{9}$. We therefore developed a diet low in saturated fat and low in carbohydrate to maximise LDL-C reduction and reduce glucose concentrations designed to achieve moderate weight loss in order to test whether the combined effects with weight loss would improve FMD.

Obesity is independently associated with increased levels of cellular adhesion molecules and weight loss has been shown to reduce them ${ }^{10,11}$. There are few studies of the effect of diet on adhesion molecules and these have examined dietary fat ${ }^{12,13}$. Adiponectin is an insulin sensitising agent which is reduced in obesity ${ }^{14,15}$. It has been shown to increase after large amounts of weight loss after gastroplasty for morbid obesity and after weight loss in subjects with diabetes but not after moderate weight loss in a short-term loss programme in non-diabetic women ${ }^{16-19}$. Macronutrient composition may also have an effect on adiponectin. Kasim-Karakas et al. ${ }^{20}$ observed a reduction in adiponectin on a eucaloric low-fat diet which returned to baseline after $6 \mathrm{~kg}$ weight loss on a low-fat diet but overall there was no improvement in adiponectin levels.

The aim of the present study therefore was to examine the effect of a low-carbohydrate compared to a conventional highcarbohydrate diet on endothelial function as assessed by FMD and levels of adhesion molecules, and adiponectin after shortterm weight loss with long-term follow-up.

We hypothesised that a low-carbohydrate weight-loss diet in comparison with a conventional high-carbohydrate, lowfat diet would be associated with improvements in FMD and adiponectin.

Abbreviations: CRP, C-reactive protein; FMD, flow-mediated dilatation; HC, high-carbohydrate diet; HDL-C, HDL-cholesterol; LC, low-carbohydrate diet; LDL-C, LDL-cholesterol; sICAM1, soluble intracellular adhesion molecule-1; sVCAM-1, soluble vascular cell adhesion molecule-1; VCAM-1, vascular cell adhesion molecule-1.

* Corresponding author: Ms Jennifer Keogh, fax +61 (0)8 83038899, email jennifer.keogh@csiro.au 


\section{Methods}

\section{Study design and subjects}

Subjects (101) were recruited by newspaper advertisement. Inclusion criteria were age 20-65 years and BMI $27-40 \mathrm{~kg} /$ $\mathrm{m}^{2}$. Exclusion criteria were diabetes mellitus or fasting glucose $>7.0 \mathrm{mmol} / \mathrm{l}$, resting blood pressure $>150 /$ $95 \mathrm{mmHg}$, medications affecting study measurements, active liver or kidney disease or malignancy, current gastrointestinal disease, pregnancy or lactation, and more than $50 \mathrm{~g}$ alcohol/d. The study protocol was approved by the Human Ethics Committee of the Commonwealth Scientific Industrial Research Organisation (CSIRO) and subjects provided informed written consent. The trial was registered with the Australian Clinical Trials Registry (N012605000614695).

Forty-four subjects were selected and matched for age, gender and BMI; seven withdrew before the study commenced for personal reasons. Twenty-five subjects (seventeen female, eight male; mean age 48.7 (SEM 1.5) years, weight 94.2 (SEM 3.5 ) $\mathrm{kg}$, BMI 32.9 (SEM 0.9) $\mathrm{kg} / \mathrm{m}^{2}$, glucose 5.9 (SEM 0.1 ) $\mathrm{mmol} / \mathrm{l}$, insulin 14.8 (SEM 2.2) mIU/l) completed the active weight-loss part of the study (12 weeks; Table 1). Two subjects were lost to follow-up, seven withdrew for personal reasons, two were unable to comply with the protocol and one withdrew for medical reasons unrelated to the study. Thirteen subjects attended for final assessments at 52 weeks.

\section{Dietary methodology}

In a randomised parallel design subjects were allocated to a weight-loss diet that was either low carbohydrate (LC; $\sim 33 \%$ energy as carbohydrate, $27 \%$ energy as fat, $40 \%$ energy as protein, $7 \%$ energy from saturated fat, $6 \%$ energy from PUFA and $13 \%$ energy from MUFA and $26 \mathrm{~g}$ fibre) or high carbohydrate $(\mathrm{HC})$, low fat $(\sim 20 \%$ energy as fat, $20 \%$ energy as protein and $60 \%$ energy as carbohydrate, $4 \%$ energy from saturated fat, $5 \%$ from PUFA and $7 \%$ from MUFA and $40 \mathrm{~g}$ fibre). Both diets were designed to be

Table 1. Baseline characteristics of subjects

\begin{tabular}{|c|c|c|c|c|}
\hline & \multicolumn{2}{|c|}{$\begin{array}{l}\text { Low-carbo- } \\
\text { hydrate diet }(n 13)\end{array}$} & \multicolumn{2}{|c|}{$\begin{array}{c}\text { High-carbo- } \\
\text { hydrate diet }(n 12)\end{array}$} \\
\hline & Mean & SEM & Mean & SEM \\
\hline Age (years) & $50 \cdot 1$ & 1.4 & $46 \cdot 9$ & $1 \cdot 6$ \\
\hline BMI $\left(\mathrm{kg} / \mathrm{m}^{2}\right)$ & $32 \cdot 6$ & 1.0 & 33.2 & 0.8 . \\
\hline Weight $(\mathrm{kg})$ & 91.5 & $4 \cdot 1$ & 97.6 & $2 \cdot 4$ \\
\hline Glucose (mmol/l) & 5.9 & 0.2 & $5 \cdot 8$ & 0.2 \\
\hline Insulin (mIU/l) & $16 \cdot 9$ & $2 \cdot 8$ & $12 \cdot 1$ & $1 \cdot 2$ \\
\hline Total cholesterol (mmol/l) & $5 \cdot 3$ & 0.2 & $5 \cdot 7$ & 0.3 \\
\hline $\mathrm{TAG}(\mathrm{mmol} / \mathrm{l})$ & $1 \cdot 7$ & 0.2 & 1.4 & 0.1 \\
\hline HDL-cholesterol (mmol/l) & $1 \cdot 3$ & 0.1 & $1 \cdot 3$ & 0.1 \\
\hline LDL-cholesterol (mmol/l) & 3.5 & 0.2 & 3.8 & 0.3 \\
\hline $\mathrm{SBP}(\mathrm{mmHg})$ & 122 & 3 & 122 & 3 \\
\hline $\mathrm{DBP}(\mathrm{mmHg})$ & 75 & 1 & 75 & 1 \\
\hline Energy (MJ) & $11 \cdot 4$ & 1.4 & $10 \cdot 8$ & $1 \cdot 2$ \\
\hline Protein (\% energy) & $19 \cdot 6$ & 0.7 & $19 \cdot 3$ & 0.9 \\
\hline Fat (\% energy) & $36 \cdot 5$ & $1 \cdot 0$ & 35.4 & 0.7 \\
\hline Carbohydrate (\% energy) & $39 \cdot 6$ & $1 \cdot 2$ & $40 \cdot 2$ & $1 \cdot 0$ \\
\hline Alcohol (\% energy) & $4 \cdot 4$ & 0.9 & $3 \cdot 3$ & 0.6 \\
\hline Fibre $(g / d)$ & 31 & 4 & 28 & 2 \\
\hline
\end{tabular}

DBP, diastolic blood pressure; SBP, systolic blood pressure. $\sim 6000 \mathrm{~kJ}$ so that weight loss would approximate $0 \cdot 5-1 \mathrm{~kg}$ per week. Records of daily food intake were maintained in order to monitor food intake and volunteers saw a dietitian individually at the start of weight loss and every 2 weeks. Volunteers attended the CSIRO clinic monthly during follow-up for a consultation with the same qualified dietitian. The dietary data were analysed using FoodWorks version 3.1 dietary analysis software (Xyris Software, Highgate Hill, Australia). In order to ensure that the energy restriction was approximately $30 \%$ below estimated usual intake a FFQ was completed at baseline to assess usual energy and nutrient intake $^{21}$ (Table 1).

\section{Weight and height}

Fasting body weight (Mercury digital scales, model AMZ14, Tokyo, Japan) was recorded in light clothing without shoes at baseline and every 2 weeks during weight loss and monthly during follow-up. Height was measured on a stadiometer (Seca, Hamburg, Germany) at baseline. BMI was calculated by weight $(\mathrm{kg}) /$ height $\left(\mathrm{m}^{2}\right)$.

\section{Resting (seated) blood pressure}

Resting blood pressure (mean of three measurements) was measured by automated oscillometry (845XT/XT-IEC, Dinamap $^{\mathrm{TM}}$, Tampa, FL, USA) with subjects in a seated position for $5 \mathrm{~min}$ at baseline and every 4 weeks and also at 6 weeks after the start of weight loss when FMD was measured.

\section{Flow-mediated dilatation}

Subjects underwent assessment of endothelium-dependent FMD of the right brachial artery, as previously described ${ }^{22}$, at baseline, after 6 weeks of intensive weight loss when dietary adherence would be at its best and glucose and LDL-C were predicted to be at their lowest level, and at 52 weeks. Subjects were kept quiet for $5 \mathrm{~min}$ before vessel diameter measurements which were taken in the morning after an overnight fast, using a $7.5 \mathrm{MHz}$ linear array transducer of an Acuson Aspen ultrasound (Siemens, Denver, CO, USA) before and after forearm ischaemia caused by inflation of a blood pressure cuff, which had been placed around the subjects' forearm approximately $2 \mathrm{~cm}$ distal to the olecranon, to $200 \mathrm{mmHg}$ for $5 \mathrm{~min}$. Measurements were also recorded for $4 \mathrm{~min}$ at $15 \mathrm{~s}$ intervals after a $300 \mu \mathrm{g}$ tablet of nitro-glycerine was administered sublingually. The operator performing the FMD procedure was blind to the dietary treatment. All FMD measurements were evaluable and none were repeated. Measurements were also recorded for $4 \mathrm{~min}$ at $15 \mathrm{~s}$ intervals after a $300 \mu \mathrm{g}$ tablet of nitro-glycerine was administered sublingually. Based on assessments performed on two separate days in nine subjects by the operator, the within-subject $\mathrm{CV}$ of the endothelium-dependent response was $8.4 \%$.

\section{Pulse wave velocity}

Aortic pulse wave velocity was measured via doppler recordings at the carotid and femoral arteries at baseline, 6, 12 and 52 weeks. Approximately ten consecutive beats were recorded to cover a complete respiratory cycle. A simultaneous 
electrocardiogram recording was used to calculate the interval between the R-wave and the upstroke of each sound wave. The difference between the average intervals for each artery was calculated. Pulse wave velocity was then determined by dividing the measured surface distance by this difference.

\section{Measurement of Augmentation Index}

Vascular measurements were performed as previously described $^{23}$ using the SphygmoCor ${ }^{\mathrm{TM}}$ blood pressure analysis system (AtCor Medical, Sydney, Australia) at baseline, 6, 12 and 52 weeks.

\section{Blood collections}

At baseline, 6, 12 and 52 weeks subjects had fasting bloods for the measurement of plasma glucose and insulin, serum total cholesterol, TAG, HDL-cholesterol (HDL-C) and LDL-C. At baseline, 12 and 52 weeks subjects had fasting blood samples taken for high-sensitivity C-reactive protein (hs-CRP), vascular cell adhesion molecule-1 (VCAM1), soluble intracellular adhesion molecule-1 (sICAM1), E-selectin, P-selectin and total adiponectin.

\section{Laboratory analysis}

Total cholesterol, HDL-C, TAG and glucose were measured using a Boehringer Mannheim/Hitachi 902 automatic analyser (Boehringer Mannheim GmbH, Mannheim, Germany) and LDL-C concentrations in serum were calculated using the Friedwald equation [(total cholesterol - HDL-C) $(\mathrm{TAG} \times 0.45)$ ]. High-sensitivity CRP concentrations were measured using a Tina-quant $\mathrm{C}$-reactive protein (latex) highsensitivity kit (Roche Diagnostics, Rotkreuz, Switzerland), with $0.03 \mathrm{mg} / \mathrm{l}$ as the lowest detection limit and an interassay $\mathrm{CV}$ of $10 \%$. Serum insulin was measured by AxSYM microparticle enzyme immunoassay, with $1.0 \mathrm{mIU} / \mathrm{l}$ as the lowest limit of detection (Mercodia Insulin ELISA cat. no. 10-1113-10' Mercodia AB, Uppsala, Sweden). Concentrations of sICAM-1, sVCAM-1, E-selectin, P-selectin and adiponectin were determined by an ELISA (ImmunoKontact, Wiesbaden, Germany).

\section{Statistics}

ANOVA with repeated measures was used. All analyses were performed using SPSS for Windows version 10.0 (SPSS Inc.,
Chicago, IL, USA) and statistical significance was set at $P<0$.05. All values are means with their standard errors unless otherwise stated.

\section{Power}

With twelve people in each group based on a CV for FMD of $10 \%$, we had sufficient power to measure a change of $12 \%$ in FMD with $80 \%$ probability and a change of $14 \%$ with $90 \%$ probability.

\section{Results}

Weight, body composition and waist circumference

When FMD was repeated at 6 weeks subjects had lost $6 \cdot 1$ (SEM 0.6) \% $(P<0.01)$ of their initial body weight with no difference between diets. After 12 weeks they had lost 8.7 (SEM 0.7$) \%(P<0 \cdot 01)$ (Table 2). Those volunteers who remained in the study for 52 weeks ( $n$ 13) lost 5.6 (SEM 1.4) $\%$ of their initial body weight with no difference between diets $(P<0 \cdot 01)$ (Table 2).

Waist circumference was also significantly reduced after 12 weeks (and remained reduced at the end of study; $P<0.01$ for time with no diet effect).

\section{Dietary intake}

Compliance with the protocol was confirmed by the dietary analysis. Energy intake and percentage energy from saturated fat were not different between the groups during the shortterm part of the study, 6262 (SEM 323) v. 6242 (SEM 352) $\mathrm{kJ}, 7.4$ (SEM 0.3) v. 3.7 (SEM 0.5), HP v. LC, respectively.

As planned, percentage energy from carbohydrate was statistically different between the groups (37.7 (SEM 1.5) v. 53.4 (SEM 1.1) \%, HP $v$. LC, respectively, $P<0.001)$. Percentage energy from protein $(35.7$ (SEM 1.1) v. 22.6 (SEM 0.7) \%, HP $v$. LC, respectively, $P<0.001)$ and total fat were also different (24.6 (SEM 0.8) v. 20.9 (SEM 1.0) \%, HP v. LC, respectively, $P<0 \cdot 01)$.

\section{Flow-mediated dilatation}

At baseline, brachial artery diameter before inflation of the cuff was 4.53 (SEM 0.21) $\mathrm{mm}$ and 4.63 (SEM 0.28) $\mathrm{mm}$, LC and $\mathrm{HC}$, respectively. There was an increase to 4.87 (SEM $0 \cdot 21) \mathrm{mm}$ and $4 \cdot 8 \cdot 4(\mathrm{SEM} 0 \cdot 28) \mathrm{mm}$ after the cuff was released,

Table 2. Anthropometric variables at 6 and 12 weeks $(n 25)$ and 52 weeks $(n$ 13)

(Mean values with their standard errors)

\begin{tabular}{|c|c|c|c|c|c|c|c|c|c|c|c|c|}
\hline & \multicolumn{4}{|c|}{6 weeks } & \multicolumn{4}{|c|}{12 weeks } & \multicolumn{4}{|c|}{52 weeks } \\
\hline & \multicolumn{2}{|c|}{ LC } & \multicolumn{2}{|c|}{$\mathrm{HC}$} & \multicolumn{2}{|c|}{ LC } & \multicolumn{2}{|c|}{$\mathrm{HC}$} & \multicolumn{2}{|c|}{ LC } & \multicolumn{2}{|c|}{$\mathrm{HC}$} \\
\hline & Mean & SEM & Mean & SEM & Mean & SEM & Mean & SEM & Mean & SEM & Mean & SEM \\
\hline $\begin{array}{l}\text { Weight change }(\mathrm{kg}) \\
\text { Waist circumference change }(\mathrm{cm})\end{array}$ & $\begin{array}{c}-5 \cdot 8^{* *} \\
\text { NA }\end{array}$ & $3 \cdot 1$ & $\begin{array}{c}-5 \cdot 9^{\star \star} \\
\text { NA }\end{array}$ & 3.7 & $\begin{array}{l}-8 \cdot 5^{\star *} \\
-4 \cdot 8^{\star *}\end{array}$ & $\begin{array}{l}4.5 \\
1.3\end{array}$ & $\begin{array}{l}-7 \cdot 9^{\star \star} \\
-6 \cdot 4^{\star \star}\end{array}$ & $\begin{array}{l}1 \cdot 1 \\
1 \cdot 1\end{array}$ & $\begin{array}{l}-4 \cdot 6^{\star \star} \\
-4 \cdot 0^{\star \star}\end{array}$ & $\begin{array}{l}2 \cdot 1 \\
1 \cdot 6\end{array}$ & $\begin{array}{l}-5 \cdot 5^{\star \star} \\
-7 \cdot 0^{\star \star}\end{array}$ & $\begin{array}{l}1 \cdot 2 \\
0 \cdot 7\end{array}$ \\
\hline
\end{tabular}

HC, high-carbohydrate diet; LC, low-carbohydrate diet; NA, not applicable.

Mean values were significantly different from those of the baseline: ${ }^{\star \star} P<0.01$ (no diet effect). 
LC and HC, respectively $(P<0 \cdot 001)$. After weight loss neither baseline nor post-ischaemic change in FMD were different, 45.8 (SEM 1.6) mm LC $v .46 \cdot 1$ (SEM 1.3) $\mathrm{mm} \mathrm{HC}$, increasing to 48.1 (SEM 1.8) mm LC $v .48 .3$ (SEM 1.3) $\mathrm{mm} \mathrm{HC}$ $(P<0.001)$, with no difference between the diet groups.

FMD did not change after weight loss of 6.1 (SEM 0.6) \% (Table 3). FMD was negatively correlated with age $(r-424$, $P<0.05)$ but there was no correlation with any other variable in particular lipid or glucose values.

FMD was not different from baseline after sustained weight loss of 5.6 (SEM 1.4) \% at the end of the study (Table 4).

\section{Resting (seated) blood pressure}

Resting systolic and diastolic blood pressure were both lower after 6 weeks of weight loss $(P<0.01)$ and remained reduced at 12 weeks $(P<0 \cdot 01)$ with no further change and no difference between diets (Table 3 ). At the end of the study diastolic blood pressure remained reduced but systolic blood pressure was not different (Table 4).

\section{Augmentation Index and pulse wave velocity}

Augmentation Index, pulse wave velocity and arterial compliance were not different compared to baseline at 12 (Table 3) or 52 weeks (Table 4).

\section{Glucose}

There was a small but statistically significant reduction in fasting glucose at 6 weeks $(-0.22($ SEM $0 \cdot 08) \mathrm{mmol} / \mathrm{l})$, with no effect of diet $(-0.28$ (SEM 0.09) v. -0.13 (SEM 0.08) $\mathrm{mmol} / \mathrm{l} \mathrm{LC} v$. HC, $P<0.05)$ ), which had rebounded somewhat at 12 weeks $(-0.18$ (SEM 0.09) mmol/l, $P=0.06$; Table 5) but there was no reduction at the end of the study (Table 6).

\section{Insulin}

Insulin was lower after 6 weeks of weight loss $(-2 \cdot 87$ (SEM $0 \cdot 10) \mathrm{mIU} / \mathrm{l}, P<0.01$, no diet effect) and was further reduced at 12 weeks $(-4.43$ (SEM 1.05) mIU/l, $P<0.001$; Table 5). At the end of the study insulin remained reduced from baseline (-4.29 (SEM 1.12) mIU/l, $P<0.001$; Table 6).

\section{Lipids}

Total cholesterol fell at 6 weeks $(-0.88$ (SEM 0.13) mmol/l, $P<0.01)$ with no difference between diets and remained reduced at 12 weeks ( -0.81 (SEM 0.14) mmol/l, $P<0.01$; Table 5) and at the end of the study ( -0.95 (SEM 0.28) $\mathrm{mmol} / \mathrm{l}, P<0 \cdot 01$; Table 6).

HDL-C fell from baseline at 6 weeks ( $-0 \cdot 10$ (SEM 0.04) $\mathrm{mmol} / 1, P<0.05$; Table 5) but was not different from baseline after 12 or 52 weeks (Table 6 ).

LDL-C was lower at 6 weeks (-0.63 (SEM 0.19) mmol/l, $P<0.01$, no effect of diet) and remained reduced at 12 $(-0.71$ (SEM 0.15$) \mathrm{mmol} / \mathrm{l}, P<0.01)$ and $52(-0.95$ (SEM $0 \cdot 27) \mathrm{mmol} / \mathrm{l}, P<0 \cdot 01$ ) weeks (Tables 5 and 6 ).

TAG was reduced at $6(-0.33($ SEM 0.01$) \mathrm{mmol} / \mathrm{l}, P<0.01)$ and remained reduced at 12 weeks $(-0.44$ (SEM 0.11$) \mathrm{mmol} / \mathrm{l}$, $P<0.01)$ with no effect of diet but was not reduced at the end of the study (Tables 5 and 6).

Adhesion molecules: soluble intracellular adhesion molecule1, soluble vascular cell adhesion molecule-1, E-selectin and $P$-selectin

There were reductions in sVCAM1 $(P<0 \cdot 05)$, sICAM $(P<0.05)$ and E-selectin $(P<0.01)$ after weight loss with no diet effect (Table 7), sICAM remained reduced at the end of the study $(P<0.05)$ whereas the change in sVCAM1 did not reach statistical significance $(P=0.08$; Table 5). E-selectin remained reduced at the end of the study $(P<0.05$; Table 7). P-selectin did not change after 12 weeks of weight loss but was reduced at the end of the study $(P<0 \cdot 05)$.

\section{Adiponectin}

Adiponectin did not change significantly after 12 weeks of weight loss although it was lower than the initial level $(P=0 \cdot 1$; Table 5$)$ but it increased at the end of the study $(P<0 \cdot 05)$. Adiponectin was negatively correlated with insulin at baseline $(r-0.485, P<0.05)$ but not at the end of the study, while HDL was positively correlated at the start and the end of the study $(r 0.630, P<0.01, r 0.778, P<0.01$, respectively). Change in adiponectin was correlated with change in insulin at the end of the study $(r 0.552, P=0.05)$ and the correlation remained significant but was slightly

Table 3. Vascular measures at 0,6 and 12 weeks ( $n$ 25)

(Mean values with their standard errors)

\begin{tabular}{|c|c|c|c|c|c|c|c|c|c|c|c|c|}
\hline & \multicolumn{4}{|c|}{0 weeks } & \multicolumn{4}{|c|}{6 weeks } & \multicolumn{4}{|c|}{12 weeks } \\
\hline & \multicolumn{2}{|c|}{ LC } & \multicolumn{2}{|c|}{$\mathrm{HC}$} & \multicolumn{2}{|c|}{ LC } & \multicolumn{2}{|c|}{$\mathrm{HC}$} & \multicolumn{2}{|c|}{ LC } & \multicolumn{2}{|c|}{$\mathrm{HC}$} \\
\hline & Mean & SEM & Mean & SEM & Mean & SEM & Mean & SEM & Mean & SEM & Mean & SEM \\
\hline FMD (\%) & $5 \cdot 3$ & 0.6 & 5.9 & 0.5 & $5 \cdot 3$ & 0.5 & $5 \cdot 0$ & 0.8 & NA & & NA & \\
\hline $\mathrm{SBP}(\mathrm{mmHg})$ & 122 & 4 & 123 & 4 & $110 \dagger$ & 4 & $115^{\star \star}$ & 4 & $111^{\star \star}$ & 4 & $118^{\star \star}$ & 5 \\
\hline $\mathrm{DBP}(\mathrm{mmHg})$ & 74 & 2 & 76 & 2 & $68 \dagger$ & 2 & $72^{\star *}$ & 1 & $67^{* *}$ & 2 & $70^{\star *}$ & 2 \\
\hline $\mathrm{Al}(\%)$ & 27 & 2 & 20 & 4 & 27 & 2 & 24 & 3 & 27 & 2 & 22 & 3 \\
\hline $\mathrm{PWV}(\mathrm{m} / \mathrm{s})$ & $9 \cdot 6$ & $1 \cdot 1$ & $10 \cdot 1$ & 0.7 & $9 \cdot 2$ & 0.5 & $8 \cdot 6$ & $2 \cdot 0$ & $10 \cdot 0$ & 0.8 & 4.9 & $2 \cdot 8$ \\
\hline
\end{tabular}

Al, Augmentation Index; DBP, diastolic blood pressure; FMD, flow-mediated dilatation; HC, high-carbohydrate diet; LC, low-carbohydrate diet; PWV, pulse wave velocity; SBP, systolic blood pressure.

Mean values were significantly different from those of the baseline ( 0 weeks): ${ }^{\star \star} P<0.01 ; \dagger P<0.05$. 
Table 4. Vascular measures at 0 and 52 weeks ( $n$ 13)

(Mean values with their standard errors)

\begin{tabular}{|c|c|c|c|c|c|c|c|c|}
\hline & \multicolumn{4}{|c|}{0 weeks } & \multicolumn{4}{|c|}{52 weeks } \\
\hline & \multicolumn{2}{|c|}{ LC } & \multicolumn{2}{|c|}{$\mathrm{HC}$} & \multicolumn{2}{|c|}{ LC } & \multicolumn{2}{|c|}{$\mathrm{HC}$} \\
\hline & Mean & SEM & Mean & SEM & Mean & $\overline{\text { SEM }}$ & Mean & SEM \\
\hline FMD (\%) & $5 \cdot 3$ & 0.8 & 7.0 & 1.3 & 4.4 & 0.7 & $4 \cdot 8$ & 0.6 \\
\hline SBP $(\mathrm{mmHg}) \dagger$ & 117 & 4 & 128 & 3 & 115 & 5 & 130 & 4 \\
\hline $\mathrm{DBP}(\mathrm{mmHg})$ & 72 & 2 & 80 & 2 & $68^{*}$ & 3 & $74^{*}$ & 3 \\
\hline $\mathrm{Al}(\%)$ & $26 \cdot 5$ & $3 \cdot 7$ & $21 \cdot 0$ & $5 \cdot 2$ & 24.4 & $2 \cdot 2$ & $22 \cdot 3$ & 4.7 \\
\hline $\mathrm{PWV}(\mathrm{m} / \mathrm{s})$ & 8.3 & 0.7 & $11 \cdot 2$ & 0.7 & $10 \cdot 3$ & 0.6 & $8 \cdot 8$ & 0.6 \\
\hline
\end{tabular}

Al, Augmentation Index; DBP, diastolic blood pressure; FMD, flow-mediated dilatation; HC, high-carbohydrate diet; LC, low-carbohydrate diet; PWV, pulse wave velocity; SBP, systolic blood pressure.

Mean values were significantly different from those of the baseline ( 0 weeks): ${ }^{\star} P<0.05$.

† SBP was different by diet at baseline and at 52 weeks in the thirteen volunteers who participated in the study until 52 weeks.

weaker after adjustment for baseline BMI $(r 0.579, P<0 \cdot 05)$. Change in adiponectin was also correlated with change in HDL ( $r$ 0.797, $P<0.01$, corrected for baseline BMI) negatively with change glucose $(r-0.617, P<0.05$, corrected for baseline BMI). Adiponectin was correlated with systolic blood pressure at baseline $(r-0.427, P<0.05)$ and 52 weeks $(r-0.554, P<0.05)$ and with diastolic blood pressure at 52 weeks $(r-0.610, P<0.05)$ but not at baseline. There were also trends towards negative correlations between change in adiponectin and change in VCAM $(r-0.524$, $P=0.08)$ and intracellular adhesion molecule-1 (ICAM; $r-0.570, P=0.05)$.

\section{C-reactive protein}

CRP did not change after 12 weeks of weight loss or at the end of the study and this remained true when subjects with CRP $>10 \mathrm{mg} / \mathrm{l}$ were excluded from the analysis (Table 7).

\section{Discussion}

The main finding of the present study was that weight loss on a low-carbohydrate diet which brought about reductions in glucose, insulin and LDL-C did not improve FMD either after short-term weight loss or long-term weight maintenance. Irrespective of diet composition weight loss had beneficial effects in the short term on adhesion molecules and blood pressure and in the longer term on adiponectin and P-selectin. There appears to be a delay in improvement in both adiponectin and P-selectin as these molecules did not in improve until weight loss had been maintained for a year.

Lack of change in FMD in the present study confirms our previous findings that weight loss does not improve FMD $^{24}$. In our previous study FMD did not change with weight loss of approximately $6 \mathrm{~kg}$ on two different low-fat diets, with reductions in TAG, insulin, CRP, plasminogen activator inhibitor-1 and sICAM1. Similarly to our results, Brook et al. ${ }^{25}$ did not demonstrate improvement in FMD following weight loss on orlistat with a reduction in LDL-C of approximately $7 \%$ and weight loss of a similar amount.

However, these findings are in contrast to studies showing a benefit on FMD of weight loss ${ }^{2,3,26,27}$. Differences between the present study and other studies include an exercise component and a much greater weight loss of $23 \mathrm{~kg}$ which may also have had an impact on the improvement in $\mathrm{FMD}^{26,27}$. Improvements in endothelial function, measured as the blood flow responses to intra-arterial acetylcholine have been observed following similar weight loss of $7 \mathrm{~kg}$ on orlistat which correlated with a reduction in LDL-C ${ }^{3}$. One of our goals with the dietary intervention was a reduction in LDL-C which we achieved, $18 \%$ at 6 weeks and nearly $30 \%$ at the end of the study with no effect on FMD.

Table 5. Glucose, insulin and lipids at 0, 6 and 12 weeks ( $n$ 25)

(Mean values with their standard errors)

\begin{tabular}{|c|c|c|c|c|c|c|c|c|c|c|c|c|}
\hline & \multicolumn{4}{|c|}{0 weeks } & \multicolumn{4}{|c|}{6 weeks } & \multicolumn{4}{|c|}{12 weeks } \\
\hline & \multicolumn{2}{|c|}{ LC } & \multicolumn{2}{|c|}{$\mathrm{HC}$} & \multicolumn{2}{|c|}{ LC } & \multicolumn{2}{|c|}{$\mathrm{HC}$} & \multicolumn{2}{|c|}{ LC } & \multicolumn{2}{|c|}{$\mathrm{HC}$} \\
\hline & Mean & SEM & Mean & SEM & Mean & SEM & Mean & SEM & Mean & SEM & Mean & SEM \\
\hline Glucose $(\mathrm{mmol} / \mathrm{l})$ & 5.90 & 0.81 & $5 \cdot 83$ & 0.41 & $5 \cdot 44^{*}$ & 0.45 & $5 \cdot 50^{*}$ & 0.52 & 5.52 & 0.42 & 5.48 & 0.48 \\
\hline Insulin (mU/ml) & $16 \cdot 88$ & 13.89 & 11.84 & 6.08 & $9 \cdot 53^{\star \star \star}$ & 6.08 & $6 \cdot 73^{\star \star \star}$ & 3.09 & $7 \cdot 97^{\star \star \star}$ & $5 \cdot 12$ & $8.96^{\star \star \star}$ & 5.44 \\
\hline Total cholesterol $(\mathrm{mmol} / \mathrm{l})$ & $5 \cdot 32$ & 0.88 & 5.73 & 1.31 & $4 \cdot 52^{\star *}$ & 0.84 & $4 \cdot 78^{\star \star}$ & 1.38 & $4 \cdot 59^{\star *}$ & 0.87 & $4 \cdot 82^{\star \star}$ & $1 \cdot 10$ \\
\hline HDL-cholesterol (mmol/l) & 1.26 & 0.31 & 1.33 & 0.31 & $1.12^{*}$ & 0.24 & $1 \cdot 26^{*}$ & 0.33 & 1.23 & 0.28 & 1.34 & 0.31 \\
\hline LDL-cholesterol (mmol/l) & 3.49 & 0.96 & 3.80 & 1.54 & $2 \cdot 86^{\star *}$ & 0.76 & $3 \cdot 01^{\star *}$ & 1.34 & $2 \cdot 88^{\star \star}$ & 0.80 & $2 \cdot 98^{\star \star}$ & 0.99 \\
\hline TAG (mmol/l) & 1.72 & 0.87 & 1.39 & 0.59 & $1 \cdot 20^{\star *}$ & 0.57 & $1 \cdot 13^{\star \star}$ & 0.52 & $1.06^{\star *}$ & 0.50 & $1 \cdot 11^{\star \star}$ & 0.61 \\
\hline
\end{tabular}

$\mathrm{HC}$, high-carbohydrate diet; LC, low-carbohydrate diet.

Mean values were significantly different from those of the baseline ( 0 weeks): ${ }^{\star} P<0.05 ;{ }^{\star \star} P<0.01 ;{ }^{\star \star \star} P<0.001$. 
Table 6. Glucose, insulin and lipids at 0 and 52 weeks $(n 13)$ (Mean values with their standard errors)

\begin{tabular}{|c|c|c|c|c|c|c|c|c|}
\hline & \multicolumn{4}{|c|}{0 weeks } & \multicolumn{4}{|c|}{52 weeks } \\
\hline & \multicolumn{2}{|c|}{ LC } & \multicolumn{2}{|c|}{$\mathrm{HC}$} & \multicolumn{2}{|c|}{ LC } & \multicolumn{2}{|c|}{$\mathrm{HC}$} \\
\hline & Mean & SEM & Mean & SEM & Mean & SEM & Mean & SEM \\
\hline Glucose (mmol/l) & $5 \cdot 37$ & 0.07 & 5.57 & 0.09 & $5 \cdot 19$ & 0.13 & $5 \cdot 50$ & 0.09 \\
\hline Insulin (mU/ml) & 11.06 & $2 \cdot 64$ & 9.09 & 0.78 & $7 \cdot 28^{\star \star \star}$ & 1.50 & $5 \cdot 22^{\star \star \star}$ & 0.49 \\
\hline Total cholesterol $(\mathrm{mmol} / \mathrm{l})$ & 5.41 & 0.23 & 6.08 & 0.52 & $4 \cdot 62^{\star \star}$ & 0.25 & $4 \cdot 94^{\star \star}$ & 0.51 \\
\hline HDL-cholesterol (mmol/l) & 1.33 & 0.08 & 1.30 & 0.08 & 1.44 & 0.14 & 1.34 & 0.07 \\
\hline LDL-cholesterol (mmol/l) & 3.48 & 0.21 & $4 \cdot 16$ & 0.49 & 2.69 & $0.29 \dagger$ & $3.01^{* *}$ & 0.42 \\
\hline $\mathrm{TAG}(\mathrm{mmol} / \mathrm{l})$ & 1.35 & 0.08 & 1.38 & 0.18 & 1.07 & 0.08 & 1.34 & 0.27 \\
\hline
\end{tabular}

HC, high-carbohydrate diet; LC, low-carbohydrate diet.

Mean values were significantly different from those of the baseline $\left(0\right.$ weeks): ${ }^{\star \star} P<0.01 ;{ }^{* \star \star} P<0.001 ; P<0.05$

Improvements in FMD which correlated with reductions in fasting glucose of $8 \%$ but not with weight loss per se or the reduction in LDL-C have also been reported ${ }^{3}$. The present study was also designed to achieve a reduction in glucose in a 6-week weight-loss intervention on a more moderate diet of $6000 \mathrm{~kJ}$ and we achieved this but with no effect on FMD. It is unclear why these conflicting results occur. Different study design and methods to assess endothelial function make it difficult to compare the studies directly.

It is perplexing that in a large $(n>2000)$ longitudinal study in young Finns there was a direct correlation between FMD and BMI whereas most studies report that obesity is associated with impaired FMD $^{3,28-30}$. The authors suggest that an increase in body size in the non-obese range is associated with physiological changes resulting in enhanced FMD. However, BMI is a surrogate measure of body fatness and there are people for whom BMI is not an appropriate measure of obesity and more direct measures of fat mass are needed $^{31,32}$.

We acknowledge that weight loss is an intervention that leads to changes in many physiological systems but the extent to which each system changes varies between individuals. A complex physiological response such as FMD may be related to LDL and glucose cross-sectionally and in post hoc analyses but these may not be causally related but correlate in some circumstances with the real unmeasured mediator of change. For instance, oxidative stress may be a major factor in reducing NO bioactivity but reducing LDL levels may have no effect on this even though the endothelial cell is clearly healthier as judged by reduced adhesion molecules.

Adiponectin rose at the end of the present study but not after short-term weight loss. With weight loss of $5 \mathrm{~kg}$ sustained at 12 months we observed a $16 \%$ increase in adiponectin, suggesting that it is sensitive to small amounts of weight loss.

Several studies have examined the effect of weight loss on adiponectin with conflicting results ${ }^{16-18,33}$. Adiponectin concentrations increased by approximately $28 \%$ after large amounts of weight loss over a long period $(39 \mathrm{~kg})$ while diet and physical activity achieved $7 \mathrm{~kg}$ weight loss and an increase in adiponectin in eight diabetic subjects but not in the group as a whole ${ }^{16,17}$. Other studies found that adiponectin levels increased in a rosiglitazone-treated group but not in a weight loss-only group or that there was no improvement in adiponectin after $7 \mathrm{~kg}$ of weight $\operatorname{loss}^{18,19}$. A low-fat diet in energy balance has been shown to decrease adiponectin by about $13 \%$ while weight loss of $6 \mathrm{~kg}$ on a low-fat diet brought adiponectin back to baseline but with no overall increase ${ }^{20}$. Therefore adiponectin did not change in three short-term and one longer-term study with moderate weight loss but increased in two long-term studies, including our own suggesting that it takes time for adiponectin production to adjust to weight loss.

We observed reductions in sVCAM1, sICAM and E-selectin after short-term weight loss and sICAM, E-selectin and P-selectin were reduced at the end of the study whereas

Table 7. Adhesion molecules soluble intracellular adhesion molecule-1 (SICAM), soluble vascular cell adhesion molecule-1 (sVCAM), E-selectin, P-selectin, adiponectin and C-reactive protein (CRP) at 0 and 12 weeks $(n 25)$ and 0 and 52 weeks $(n 13)$

(Mean values with their standard errors)

\begin{tabular}{|c|c|c|c|c|c|c|c|c|}
\hline & \multicolumn{2}{|c|}{0 weeks } & \multicolumn{2}{|c|}{12 weeks } & \multicolumn{2}{|c|}{0 weeks } & \multicolumn{2}{|c|}{52 weeks } \\
\hline & Mean & SEM & Mean & SEM & Mean & SEM & Mean & SEM \\
\hline sVCAM1 (ng/ml) & 843 & 39 & $793^{*}$ & 33 & 778 & 40 & 726 & 185 \\
\hline sICAM (ng/ml) & 340 & 20 & $294^{\star}$ & 18 & 345 & 34 & $316^{\star}$ & 42 \\
\hline E-selectin (ng/ml) & 84 & 8 & $72^{* *}$ & 7 & 79 & 11 & $71^{*}$ & 12 \\
\hline P-selectin (ng/ml) & 166 & 15 & 169 & 22 & 150 & 16 & $127^{\star}$ & 15 \\
\hline Adiponectin $(\mathrm{ng} / \mathrm{ml})$ & 6992 & 684 & 6598 & 590 & 5983 & 742 & $7004^{*}$ & 993 \\
\hline CRP (mg/l) & 3.57 & 1.0 & 3.76 & 1.38 & 1.87 & 0.3 & $2 \cdot 44$ & 0.6 \\
\hline
\end{tabular}

Mean values were significantly different from those of the baseline $\left(0\right.$ weeks): ${ }^{*} P<0.05 ;{ }^{*} P<0.01$ 
VCAM1 was not but this may be due to the small sample size. This has also been observed by others ${ }^{10,34,35}$.

\section{Limitations of the study}

We estimated that for the short-term part of the study we had sufficient power to measure a change of $12 \%$ in FMD with $80 \%$ probability. However, this is still a relatively small study and we had a higher than anticipated dropout rate during the follow-up, making the long-term results less robust. The numbers of subjects are similar to the subject numbers in other studies in which FMD improved with weight loss (e.g. Hamdy et al. ${ }^{26}$, $n$ 24; Vazquez et al. ${ }^{36}$, $n$ 26) but smaller that other studies (e.g. Raitakari et al. ${ }^{3}$, $n$ 67; Shechter et al. ${ }^{37}, n$ 80). In one study the subject numbers are smaller $(n 6)$ than in the long-term part of the present study, however weight loss, $23 \mathrm{~kg}$, was much greater ${ }^{27}$.

We acknowledge that a relatively small sample size and higher than anticipated dropout rate is a limitation of the study.

In conclusion, weight loss on a low-carbohydrate, low-saturated fat diet, does not improve FMD despite improvement in cardiovascular risk factors. The improvement in adiponectin was delayed.

\section{Acknowledgements}

We thank the Diabetes Australia Research Trust (DART) for partial financial support for the trial. We also acknowledge the contribution to the conduct of the trial of Anne McGuffin, Kathryn Bastiaans, Julia Weaver, Rosemary McArthur, Candita Sullivan and Julie Turner.

\section{References}

1. Hashimoto M, Akishita M, Eto M, Kozaki K, Ako J, Sugimoto N, Yoshizumi M, Toba K \& Ouchi Y (1998) The impairment of flow-mediated vasodilatation in obese men with visceral fat accumulation. Int J Obes Relat Metab Disord 22, 477-484.

2. Bergholm R, Tiikkainen $M$, Vehkavaara S, Tamminen $M$, Teramo K, Rissanen A \& Yki-Jarvinen H (2003) Lowering of LDL cholesterol rather than moderate weight loss improves endothelium-dependent vasodilatation in obese women with previous gestational diabetes. Diabetes Care 26, 1667-1672.

3. Raitakari M, Ilvonen T, Ahotupa M, Lehtimaki T, Harmoinen A, Suominen P, Elo J, Hartiala J \& Raitakari OT (2004) Weight reduction with very-low-caloric diet and endothelial function in overweight adults: role of plasma glucose. Arterioscler Thromb Vasc Biol 24, 124-128.

4. Fuentes F, Lopez-Miranda J, Sanchez E, et al. (2001) Mediterranean and low-fat diets improve endothelial function in hypercholesterolemic men. Ann Intern Med 134, 1115-1119.

5. Ros E, Nunez I, Perez-Heras A, Serra M, Gilabert R, Casals E \& Deulofeu R (2004) A walnut diet improves endothelial function in hypercholesterolemic subjects: a randomized crossover trial. Circulation 109, 1609-1614.

6. de Roos NM, Bots ML, Siebelink E, Schouten E \& Katan MB (2001) Flow-mediated vasodilation is not impaired when HDL-cholesterol is lowered by substituting carbohydrates for monounsaturated fat. Br J Nutr 86, 181-188.

7. Keogh JB, Grieger JA, Noakes M \& Clifton PM (2005) Flow-mediated dilatation is impaired by a high-saturated fat diet but not by a high-carbohydrate diet. Arterioscler Thromb Vasc Biol 25, 1274-1279.

8. Poobalan A, Aucott L, Smith WC, Avenell A, Jung R, Broom J \& Grant AM (2004) Effects of weight loss in overweight/obese individuals and long-term lipid outcomes - a systematic review. Obes Rev 5, 43-50.

9. Mensink RP, Zock PL, Kester AD \& Katan MB (2003) Effects of dietary fatty acids and carbohydrates on the ratio of serum total to HDL cholesterol and on serum lipids and apolipoproteins: a meta-analysis of 60 controlled trials. Am J Clin Nutr 77, 1146-1155.

10. Ferri C, Desideri G, Valenti M, Bellini C, Pasin M, Santucci A \& De Mattia G (1999) Early upregulation of endothelial adhesion molecules in obese hypertensive men. Hypertension 34, 568-573.

11. Miller MA \& Cappuccio FP (2006) Cellular adhesion molecules and their relationship with measures of obesity and metabolic syndrome in a multiethnic population. Int J Obes (Lond) 30, 1176-1182.

12. Bemelmans WJ, Lefrandt JD, Feskens EJ, Broer J, Tervaert JW, May JF \& Smit AJ (2002) Change in saturated fat intake is associated with progression of carotid and femoral intimamedia thickness, and with levels of soluble intercellular adhesion molecule-1. Atherosclerosis 163, 113-120.

13. Perez-Jimenez F, Castro P, Lopez-Miranda J, et al. (1999) Circulating levels of endothelial function are modulated by dietary monounsaturated fat. Atherosclerosis 145, 351-358.

14. Ukkola O \& Santaniemi M (2002) Adiponectin: a link between excess adiposity and associated comorbidities? J Mol Med $\mathbf{8 0}$, 696-702.

15. Bluher M, Fasshauer M, Tonjes A, Kratzsch J, Schon MR \& Paschke R (2005) Association of interleukin-6, C-reactive protein, interleukin-10 and adiponectin plasma concentrations with measures of obesity, insulin sensitivity and glucose metabolism. Exp Clin Endocrinol Diabetes 113, 534-537.

16. Kopp HP, Krzyzanowska K, Mohlig M, Spranger J, Pfeiffer AF \& Schernthaner G (2005) Effects of marked weight loss on plasma levels of adiponectin, markers of chronic subclinical inflammation and insulin resistance in morbidly obese women. Int J Obes (Lond) 29, 766-771.

17. Monzillo LU, Hamdy O, Horton ES, et al. (2003) Effect of lifestyle modification on adipokine levels in obese subjects with insulin resistance. Obes Res 11, 1048-1054.

18. Dvorakova-Lorenzova A, Suchanek P, Havel PJ, Stavek P, Karasova L, Valenta Z, Tintera J \& Poledne R (2006) The decrease in C-reactive protein concentration after diet and physical activity induced weight reduction is associated with changes in plasma lipids, but not interleukin-6 or adiponectin. Metabolism 55, 359-365.

19. Abbasi F, Chu JW, Lamendola C, McLaughlin T, Hayden J, Reaven GM \& Reaven PD (2004) Discrimination between obesity and insulin resistance in the relationship with adiponectin. Diabetes 53, 585-590.

20. Kasim-Karakas SE, Tsodikov A, Singh U \& Jialal I (2006) Responses of inflammatory markers to a low-fat, high-carbohydrate diet: effects of energy intake. Am J Clin Nutr 83, 774-779.

21. Hodge A, Patterson AJ, Brown WJ, Ireland P \& Giles G (2000) The Anti Cancer Council of Victoria FFQ: relative validity of nutrient intakes compared with weighed food records in young to middle-aged women in a study of iron supplementation. Aust N Z J Public Health 24, 576-583.

22. Anderson TJ, Uehata A, Gerhard MD, et al. (1995) Close relation of endothelial function in the human coronary and peripheral circulations. J Am Coll Cardiol 26, 1235-1241.

23. van Trijp MJ, Beulens JW, Bos WJ, Uiterwaal CS, Grobbee DE, Hendriks HF \& Bots ML (2005) Alcohol consumption and 
augmentation index in healthy young men: the ARYA study. Am J Hypertens 18, 792-796.

24. Clifton PM, Keogh JB, Foster PR \& Noakes M (2005) Effect of weight loss on inflammatory and endothelial markers and FMD using two low-fat diets. Int J Obes (Lond) 29, 1445-1451.

25. Brook RD, Bard RL, Glazewski L, Kehrer C, Bodary PF, Eitzman DL \& Rajagopalan S (2004) Effect of short-term weight loss on the metabolic syndrome and conduit vascular endothelial function in overweight adults. Am J Cardiol 93, $1012-1016$

26. Hamdy O, Ledbury S, Mullooly C, et al. (2003) Lifestyle modification improves endothelial function in obese subjects with the insulin resistance syndrome. Diabetes Care 26, 2119-2125.

27. Williams IL, Chowienczyk PJ, Wheatcroft SB, Patel AG, Sherwood RA, Momin A, Shah AM \& Kearney MT (2005) Endothelial function and weight loss in obese humans. Obes Surg 15, 1055-1060.

28. Benjamin EJ, Larson MG, Keyes MJ, et al. (2004) Clinical correlates and heritability of flow-mediated dilation in the community: the Framingham Study. Circulation 109, 613-619.

29. Steinberg HO, Chaker H, Leaming R, et al. (1996) Obesity/insulin resistance is associated with endothelial dysfunction. J Clin Invest 97, 2601-2610.

30. Suwaidi JA, Higano ST, Holmes DRJ, et al. (2001) Obesity is independently associated with coronary endothelial dysfunction in patients with normal or mildly diseased coronary arteries. J Am Coll Cardiol 37, 1523-1528.
31. Nevill AM, Stewart AD, Olds T \& Holder R (2006) Relationship between adiposity and body size reveals limitations of BMI. Am J Phys Anthropol 129, 151-156.

32. Prentice AM \& Jebb SA (2001) Beyond body mass index. Obes Rev 3, 141-147.

33. Abbasi F, Lamendola C, McLaughlin T, Hayden J, Reaven GM \& Reaven PD (2004) Plasma adiponectin concentrations do not increase in association with moderate weight loss in insulinresistant, obese women. Metabolism 53, 280-283.

34. Pontiroli AE, Pizzocri P, Koprivec D, Vedani P, Marchi M, Arcelloni C, Paroni R, Esposito K \& Giugliano D (2004) Body weight and glucose metabolism have a different effect on circulating levels of ICAM-1, E-selectin, and endothelin-1 in humans. Eur J Endocrinol 150, 195-200.

35. Ziccardi P, Nappo F, Giugliano G, Esposito K, Marfella R, Cioffi M, D’Andrea F, Molinari AM \& Giugliano D (2002) Reduction of inflammatory cytokine concentrations and improvement of endothelial functions in obese women after weight loss over one year. Circulation 105, 804-809.

36. Vazquez LA, Pazos F, Berrazueta JR, Fernandez-Escalante C, Garcia-Unzueta MT, Freijanes J \& Amado JA (2005) Effects of changes in body weight and insulin resistance on inflammation and endothelial function in morbid obesity after bariatric surgery. J Clin Endocrinol Metab 90, 316-322.

37. Shechter M, Freimark D, Beigel R, Matetzky S \& Feinberg MS (2006) Short-term sibutramine therapy is associated with weight loss and improved endothelial function in obese patients with coronary artery disease. Am J Cardiol 97, 1650-1653. 